\title{
O Suicídio e suas relações com a psicopatologia: análise qualitativa de seis casos de suicídio racional
}

\author{
Suicide and its psychopathological relations: \\ a qualitative analysis of 6 rational suicidal \\ patients
}

\footnotetext{
1 Hospital do Servidor Público Estadual de São Paulo. Rua Urussuí, 71 conj. 133m, Itaim Bibi, São Paulo, SP 04542-050, Brasil.
}

\begin{abstract}
We studied the meaning given to the terms "death" and "suicide" among psychiatric inpatients. Forty-four patients who had been admitted in a psychiatric inpatient unit following a suici de attempt underwent a qual itati ve interview, using a "general gui de intervi ew" approach. The results were analysed systematically in an attempt to investigate the relationship between attempted suici de and mental disorder. In 6 cases there was no correl ation between the attempted suici de and psychopathological symptoms. One of these patients had a psychiatric diagnosis, but this did not seem to be related to the suicide attempt. All of them made a rational deliberate suicidal act. Conclusion: even in a psychiatric inpatient setting, suicide attempts are not al ways a behavioural expression of underlying psychopathological disturbances - individual and social factors also play a decisive role.

Key words Suicide; Attempted Suicide; Psychopathology
\end{abstract}

Resumo Foram avaliados sistematicamente 44 pacientes, admitidos em enfermaria psiquiátrica de hospital geral logo após tentativa de suicídio. Estes indivíduos foram submeti dos a entrevista qualitativa, usando-se um guia geral de entrevista. Os resultados foram avaliados, procurando-se referir a tentativa de suicídio a uma patologia psiquiátrica. Em seis casos, não se encontrou relação entre tentativa de sui cídio e doença mental. Um destes pacientes tinha história de doença psiquiátrica prévia, porém não foi possível ligar o sui cídio a esta. A análise de conteúdo destes casos por meio de um enfoque fenomenológi co-existencial procurou estabelecer os significados da tentativa de sui cídio para cada paciente. O autor concluiu que as tentativas de suicídio nem sempre expressam doença mental subjacente e que fatores sociais e indi viduais podem exercer papel decisivo. Assi m, estudos clínicos e epidemi ológi cos concernentes ao suicídi o deverse-iam basear em conceitos mais sólidos.

Palavras-chave Suicídio; Tentativa deSuicídio; Psicopatologia 
Introdução

O suicídio é ato humano complexo e, embora as tentativas sejam freqüentes, raros são os casos que resultam em óbito. Contudo, os números vêm aumentando de maneira consi derável. Para al guns autores, o crescimento das taxas de suicídio é de $200 \%$ a $400 \%$ nos últimos vinte anos, em particular, entre os adolescentes (Klerman \& Weissman, 1989; Goodwin \& Runk, 1992). A Organização Mundial da Saúde avalia o suicídio como problema de saúde pública, pois configura uma entre as dez causas mais freqüentes de morte em todas as idades, da mesma forma que é a segunda ou terceira causa de morte entre 15 e 34 anos de idade (Retterstol, 1993). Estima-se que, para cada suicídio, existem pelo menos dez tentativas suficientemente sérias ao ponto de exigir atenção médica; mais ainda: para cada tentativa de suicídio registrada, existem quatro não conhecidas (Diekstra, 1993). As relações entre idade e sexo e suicídio, assim como a freqüência destes, variam muito no que concerne ao país estudado. De maneira geral, é mais comum entre os homens com idade entre 25 e 35 anos, ao passo que as tentativas de suicídio são mais usuais em mulheres com idade entre 18 e 30 anos. Há alguns indicadores de suicídio, embora novamente não se obtenha consenso entre os autores: o suicídio estaria altamente relacionado aos desempregados, brancos, com patologia psiquiátrica, uso de álcool e drogas, tal como com tentativa de suicídio anterior. Entre as pessoas que tentam o suicídio é comum a presença de problemas psicossociais, tais como: separações, perdas de pessoas queridas e perda de emprego (Van Egmond \& Diekstra, 1989).

O suicídio está bastante relacionado a vários tipos de doença. Já foi referido, entre outras, à AIDS, a pós acidente vascular cerebral, ao infarto do miocárdio, à esclerose múltipla, à doença de Parkinson e à insuficiência respiratória crônica de diversas etiologias. Dentre as doenças, as psiquiátricas são as mais relatadas. Os resultados entre os vários pesquisadores, no entanto, são discrepantes, colocando-se como prevalentes: a depressão, a ansiedade, os delírios, os transtornos de personalidade e o uso de substâncias psicoativas (incluindo o álcool). Dependendo do autor, uma delas encabeça a lista.

A freqüência do suicídio entre as patologias também é bastante variável; por exemplo, a depressão pode ser responsável por $45 \%$ a $70 \%$ dos suicídios. Esta é, sem dúvida, a causa preferida pelos autores como a maior responsável pelo suicídio, chegando alguns deles a afirmar que suicídio é sinônimo de depressão (Barraclough \& Hughes, 1987; Murphy \& Wetzel, 1990).

Esta tendência, por parte da literatura psiquiátrica, de sempre associar o suicídio à doença mental, principalmente à depressão, é questionável. A ideação suicida e a tentativa de suicídio são critérios diagnósticos desta doença nos códigos vigentes. É difícil imaginar, entretanto, que a pessoa que sobrevive a uma tentativa de suicídio não esteja desanimada, frustrada. Assim, o diagnóstico de depressão, nestes casos, é delicado. Em trabalho anterior (Mello, 1992) encontrou-se maior freqüência de diagnósticos de depressão entre suicidas sem diagnóstico psiquiátrico prévio.

O pressuposto teórico de que este ato está sempre relacionado à doença mental pode, por um lado influenciar a postura do médico diante do suicídio e, por outro, na clínica, atitudes por vezes inadequadas podem ser impostas, como a retirada da autonomia do paciente mediante o uso de medicações antidepressivas em condições não tão claras. Tal questão é igualmente crucial para aqueles que elaboram estratégias para a prevenção do suicídio. Estudos mostram que certo número de suicidas passa por consultas médicas pouco antes do mesmo, porém maior número ainda não o faz. A prevenção, dependendo do nível que se deseja atingir, não pode ser baseada exclusivamente em dados das doenças supostamente relacionadas.

Na polêmica concernente ao suicídio ser sempre motivado ou não pela doença mental, vários autores de peso colocam-se em cada um dos lados. Goodwin \& Runk (1992) afirmam que a maioria dos suicidas estão doentes mentais no momento do ato, mas têm conhecimento de que há diversidade conceitual entre os pesquisadores. Por seu lado, Hawton \& Catalan (1987) acham que não devem ser avaliados como doentes mentais aqueles que tentam o suicídio. Henrikson et al. (1993) registraram o suicídio não patológico em $2 \%$ dos casos, todavia citam trabal hos clássicos que colocam os valores dos suicídios racionais entre 0 e $12 \%$. Aratò et al. (1988), por sua vez, encontraram suicídio racional em $19 \%$ dos suicídios na Hungria. Carneiro \& Figueiroa (1994) classificam o suicídio como sinônimo de depressão maior e recomendam tratamento preventivo neste caso, havendo ou não risco de suicídio.

Desse modo, as relações entre suicídio e doença mental são confusas. Robins et al. (1959) e Barrraclough et al. (1974) mostram altas taxas de doença mental entre os suicidas (avaliação retrospectiva), 94\% e 93\% respectivamente. Black \& Winokur (1990) encontraram 90\% de 
pacientes psiquiátricos entre o suicidas. Cheng (1995) encontrou doença mental em $97 \%$ a $100 \%$ dos suicidas de Formosa.

King (1994) estudou o suicídio em pacientes recém atendidos por psiquiatras, encontrando $90 \%$ dos casos com psicopatologia severa. Dentre os 286 suicídios e mortes indeterminadas (open-verdict) da área do Reino Unido pesquisada entre 1991 e 1994, a amostra estudada correspondia a 108 destes casos. O autor não se aprofundou nos 168 casos - não era este o seu objetivo - que nunca foram vistos, com relação a estes problemas, por profissionais da área de saúde mental ou por seus clínicos.

Os estudos retrospectivos, por si sós, fundamentados em dados colhidos entre familiares e médicos que acompanhavam os casos (autópsia psicológica) não deixam de ser suspeitos no que diz respeito à avaliação de situação tão contaminada do ponto de vista emocional.

Matthews et al. (1994), levantando todos os casos de morte por suicídio na Escócia durante 1988 e 1989, procuraram anotações a respeito destes a partir de seus médicos (general practicioners) na atenção primária. Constataram que somente aqueles com passado psiquiátrico procuraram tratamento, o que grande parte dos suicidas não fizera. Concluíram que o trabalho de prevenção do suicídio não deveria estar centrado na atenção primária e que apenas pacientes com doença psiquiátrica podem ser atingidos neste nível de prevenção.

Apesar das discrepância entre os resultados encontrados e o aumento da freqüência do suicídio, os autores continuam a fazer pesquisas, confirmando hipóteses que, logo em seguida, são rejeitadas por outros. Em vista disso, resolvemos examinar a questão mediante estudo qualitativo que enfoca o significado da morte e do suicídio para os pacientes (M ello, 1995).

\section{Material e métodos}

Todos os pacientes internados na enfermaria de psiquiatria do Hospital do Servidor Público Estadual por uma tentativa de suicídio durante o período de seis meses foram submetidos a entrevista qualitativa por psiquiatra treinado, desde que os pacientes preenchessem os critérios de inclusão no estudo. Eram critérios de inclusão: admissão em enfermaria psi quiátrica após tentativa de suicídio e o consentimento do paciente para a participação no estudo, seguido de assinatura em termo de consentimento. Eram critérios de exclusão: presença de confusão e de deficiências intelectuais ou neurológicas que levassem a dificuldades cogniti- vas e/ ou expressivas. Desta forma foram sistematicamente incluídos 44 pacientes no estudo.

\section{Procedimentos}

Assim que o paciente entrava no estudo, completava-se um inventário sociodemográfico. Na admissão e na saída fazia-se, ou não, um diagnóstico psiquiátrico por meio de entrevistas psiquiátricas não estruturadas, conduzidas por psiquiatra cego quanto aos resultados da entrevista qualitativa. Um guia geral de entrevista (general guide interview) era então aplicado por psiquiatra pesquisador treinado. Após a coleta dos dados, os resultados eram analisados com relação ao conteúdo dos mesmos. As seguintes questões eram então pesquisadas:

- O paciente tinha algum sintoma psicopatológico durante a tentativa de suicídio?

- Tinha o paciente algum diagnóstico psiquiátrico prévio?

- Era este relacionado à tentativa de suicídio?

- Era a tentativa de suicídio um sintoma da doença psiquiátrica?

A análise do conteúdo era sistematizada. Destacava-se cada sentença do material obtido durante as entrevistas relacionadas às questões pesquisadas e tentava-se encontrar coerência interna entre elas.

\section{Instrumento}

Foi usado um enfoque chamado "guia geral de entrevistas", uma entrevista qual itativa intermediária entre entrevista padronizada com começo e fim e uma conversa informal. Esta caracteriza-se por tópicos previamente determinados a serem explorados por cada paciente (Patton, 1990). Não existem questões escritas padronizadas nem disposi ção rígi da de formulação destas. As questões versam a respeito das opiniões e valores dos pacientes quanto a sua tentativa de suicídio. O entrevistador pode adaptar a seqüência e as questões formuladas, dependendo do contexto da entrevista. O instrumento foi aplicado durante o seguimento de quatro entrevistas com cerca de uma hora cada.

A primeira entrevista começava com apresentação do entrevistador e das metas do estudo. Assegurava-se que o conteúdo das entrevistas seria confidencial, enfatizando-se sempre a neutralidade do entrevistador. No começo de cada entrevista eram apresentadas algumas questões gerais relativas a hospital ização, tratamentos, atividades, medicação etc. Todas estas medidas tinham como finalidade proporcionar melhores condições para a entrevista. 
Evitavam-se questões dicotômicas, preferindose aquelas que buscassem as opiniões dos pacientes.

Todas as entrevistas foram anotadas, grifando-se tópicos e frases significativas durante a mesma. Convencionou-se que o entrevistador colocaria entre aspas somente as frases ditas pelo entrevistado, marcando as interpretações, pensamentos e idéias que vinham durante a entrevista. Logo que a entrevista terminava, o entrevistador fazia extensa dissertação acerca do material anotado. As dissertações eram então analisadas para responder as questões previamente estabelecidas.

A análise do conteúdo das entrevistas foi feita a partir do método fenomenológico-existencial. O método fenomenológico aqui referenciado é baseado em Husserl (1931, apud Melo, 1981) e voltado para a captação e compreensão das estruturas e modos de organização intencional da consciência, levando, por meio da redução, à distinção entre o fato e a essência. O fato é empírico, temporal, individual, contingente, local izável e variável com as circunstâncias. A essência é intemporal e universal, sempre una e autêntica, idêntica e imutável. Pressupõe-se que para todo fato há uma essência. Na redução fenomenológica procurase, por intermédio da suspensão dos juízos, apreender o fenômeno, em sua estrutura essencial, obtida mediante reflexão e intuição.

O método fenomenológico de Husserl desemboca na análise existencial como estrutura do ser-no-mundo, descrita por Heidegger (1935, apud Melo, 1981), e em uma série de outras concepções narradas como fenomenológicasexistenciais. Interessa-nos compreender, na anál ise dos conteúdos das entrevistas, as relações entre a atitude suicida e a história do indivíduo. Procuramos saber quais os significados atribuídos por estes pacientes à morte e ao suicídio, avaliando, neste contexto, se foram escoIhas deliberadas, opções, ou se foram impostas por processo psicopatológico.

A análise do conteúdo segundo método qualitativo é tomado mais recentemente, pela Sociologia, como um conjunto de técnicas de análise das comunicações (Bardin, 1977). Com base neste enfoque, a análise de conteúdo realizada consistiu em uma descrição analítica, uma análise dos significados em comunicação dual, utilizando-se a linguagem oral e a não verbal coletadas nas entrevistas acima descritas, para então passar às inferências acerca do material, como o que conduziu à determinação de tal enunciado. Por fim, as interpretações/significações concedidas a estas características tiveram lugar.

\section{Resultados}

A análise das entrevistas qualitativas mostrou que, em seis casos, nenhum sintoma psicopatológico foi encontrado durante a tentativa de suicídio e previamente a esta. A tentativa foi considerada como escolha livre e premeditada, não relacionada a doença mental, classificando-se então como suicídio racional. Um dos casos apresentava diagnóstico psiquiátrico anterior, porém a atual tentativa de suicídio não foi a este referida. Tratava-se de uma professora de 2 o grau, em atividade, com quadro delirante crônico (erotomania) sem prejuízos funcionais. Após receber diagnóstico de leucemia linfóide tentou o suicídio por imolação. Dois anos antes, essa paciente havia cuidado de uma irmã com idêntico tipo de diagnóstico e optou por não sofrer da mesma maneira, apavorandoIhe o fato de estar sozinha. Dez dias após a última entrevista, morreu na UTI em conseqüência de sua tentativa de suicídio.

Uma outra paciente realizou grave tentativa de suicídio por ingestão de medicamentos. Disse ter feito tal tentativa porque nada mais tinha a fazer na vida. Desde a morte de seu marido - há vinte anos - passara a sustentar a casa e os dois filhos, tendo sido bem sucedida nesta tarefa apesar das dificuldades. Nos últimos anos, o filho começara a trabal har com a paciente, que Ihe ensinara a profissão, passando-Ihe muitos clientes. Mais recentemente, o filho passou a tomar conta do negócio sozinho, dando mesada à mãe, por não querer que a mesma continuasse a trabal har. A paciente acreditava que ele assim agia para controlar seu dinheiro. Reclamava do fato de não saber o montante da conta bancária dele e, principalmente, por ter que pedir-Ihe dinheiro. Acrescentou que seu fiIho sempre Ihe deu tudo, mas que isto a fazia sentir-se humilhada. Sempre tivera boa posição social até a morte do marido, além de ter sido mulher bonita, culta e inteligente, "por isto sempre consegui muita coisa na vida...". A sua relação com o filho era conturbada por intrometer-se em suas relações amorosas. O fiIho, ao mesmo tempo em que permitia tal ingerência, agredia a mãe verbalmente e, por vezes, até fisicamente. Anteriormente, a paciente nunca se tratara do ponto de vista psíquico. Não se demonstrou deprimida durante o exame; sua tentativa de suicídio fora intencional, com o fim real de auto eliminação, apesar de mostrar forte conteúdo histriônico pelo sentido de incutir culpa em seu filho. Inquirida a respeito do significado de seu ato, alegou que queria morrer, pois não havia mais nada a fazer; protestava assim contra a situação que lhe 
era imposta. "Semprefiz o que quis! Este seria o meu último ato, mas deixaria muita gentecom remorsos". Não parecia se preocupar com o que aconteceria depois da morte, pois, apesar de ser judia, não era religiosa: “...acabamos aqui...". Falava de seu ato sem demonstrar envolvimento afetivo. Não foi possível detectar patologia psiquiátrica envolvida no suicídio.

Outro paciente avaliado, um adolescente de 16 anos, mostrou-se reticente, não querendo falar no motivo que o levara a realizar tal ato. Não apresentava déficit de consciência, alterações cognitivas ou, ainda, do humor. Pela história de vida colhida tanto com o paciente quanto com a família, é provável que a tentativa de suicídio - gravíssima, com arma de fogo tenha sido motivada por conflito. O projétil alojou-se no crânio e foi retirado por neurocirurgia, não ocasionando lesões nem mesmo déficits neurológicos no pós operatório. O rapaz, nas avaliações seguintes, expôs a causa como amor platônico, não correspondido, tendo planejado uma solução romântica. Estava consciente de sua atitude e da escolha que havia feito. Não sabia ainda o que iria fazer com tal insucesso.

Um homem, ao redor de seus 40 anos de idade, tentou o suicídio pela ingestão de psicofármacos. A motivação foi uma situação social e afetiva que se tornara insuportável, em virtude de problemas que se arrastavam há anos. Ao chegar em São Paulo, há mais de dez anos, "inventara" uma história de sua vida pregressa, omitindo a humilde origem familiar. Mantivera esta mentira desde então; porém, desde algum tempo, a história tornara-se complicada. Seu companheiro suspeitara da veracidade dos fatos e, muitas vezes, o paciente entrara em contradições diante dele. Tinha medo de revelar a verdade em razão de serem imprevisíveis as conseqüências, pela vergonha de ter mantido uma farsa tão "tola", segundo o próprio, mesmo para seu companheiro há seis anos. Optou pelo suicídio, pois contar Ihe seria penoso. Em processo psicoterápico posterior às entrevistas, conseguiu rever suas relações familiares, o porquê de tê-las abandonado, culminando com a procura bem sucedida da família. Paralelamente, o fato foi exposto pelo paciente ao companheiro, o qual, para sua surpresa, não se mostrou abalado, uma vez que já sabia do fato, e o ajudou a procurar a família.

Uma paciente jovem, de 20 anos de idade, realizou tentativa de suicídio por ingestão de psicofármacos. Contou inicialmente estar arrependida e envergonhada de seu ato. Não conseguira suportar seus sentimentos nem tivera coragem de enfrentá-los. Vinha de um namoro de quatro anos de duração. Esse relacionamento era estável, mas algo monótono em seu modo de entender. Durante férias que desfrutou com amigas, manteve relacionamento por quase todo o período com outro rapaz, sentindo forte atração física por ele, o que até então não era conhecido pela paciente. Este caso fora presenciado e até incentivado pelas amigas. Contudo, ao regressar, desenvolvera intenso remorso, e resolvera contar ao namorado, o qual imediatamente rompera o relacionamento. A partir de então, seus sentimentos foram de raiva de si mesma, vergonha, culpa e falta de coragem para resolver a situação, uma vez que várias pessoas em comum tinham sido envolvidas. No clímax desta situação ingeriu medicamentos com o intuito de matar-se. Via o suicídio como maneira de fugir da situação, tendo optado pelo não enfrentamento como saída mais rápida para tudo.

Outra paciente, mulher casada de 38 anos, tentou o suicídio mediante ingestão de psicofármacos. Ao ser descoberta, foi levada pela família ao pronto-socorro. Dizia não suportar, em sua vida, uma série de dificuldades: conjugais, econômicas e pessoais. Estas se arrastavam há anos e sabia que não seriam solucionadas tão brevemente. Não se sentia triste ou deprimida, porém não tinha perspectivas de solução, o que era realmente difícil pelas circunstâncias. Optou pelo suicídio, pois esta saída teria desfecho conhecido: a morte.

\section{Discussão}

A partir desses achados confirmamos que o suicídio nem sempre é resultante de doença mental. Para nós, a doença mental acontece quando a pessoa perde a capacidade de escolher e agir de acordo com a sua vontade. A doença limita a liberdade da pessoa para agir, tal como quando se deixa de sair por medo de sofrer ataque de pânico, ou de realizar uma vontade por achar que o mundo irá logo acabar, ou ter que agredir uma pessoa por estar sendo comandado por vozes. Deste modo, a doença mental ocorre quando se perde a liberdade de escolha (Sonenreich \& Bassit, 1979). No caso do suicídio patológico, a morte não configura uma escolha deliberada, mas é ação norteada pela doença. Sem dúvida, a doença mental acarreta maior possibilidade de suicídio, constituindo um dos fatores preditivos mais poderosos ao lado de prévia tentativa de suicídio; porém, nem todos os suicidas estão doentes mentais.

Em um dos trabalhos estudados (HortonDeutsh et al., 1992), os autores explicitam a al- 
ta incidência de suicídio em pacientes com dispnéia crônica. Um destes, homem idoso que sempre fora ativo, trabal hara e praticara esportes até sobrevir infarto extenso. Era definido pelos autores como sério, equilibrado, quieto e confiante. $\mathrm{Na}$ fase de recuperação, mantivera grande parte de suas atividades enquanto seguia o tratamento. Com o progredir da doença coronária, suas limitações foram aumentando, manifestando-se intensa dispnéia. Nos últimos dois meses de vida sofrera duas internações por fibrilação atrial, edema pulmonar e insuficiência renal. Até para a alimentação ficava dispnéico. Pedira alta precoce, confidenciando à enfermeira que não acreditava em melhora. Uma semana antes do suicídio fora visto por seu médico, o qual Ihe confirmara o prognóstico. No dia seguinte matouse com um tiro na cabeça.

Os autores afirmam o diagnóstico de depressão com base na anedonia, diminuição do apetite e isolamento. Contudo, que prazer, que apetite, que condições teria semelhante pessoa para conversar em seu estado atual? Principalmente por tratar-se de paciente que sempre fora auto-suficiente física e emocional mente. $\mathrm{O}$ diagnóstico de depressão é, ao nosso ver, questionável.

Alguns suicídios de pessoas famosas, como o de Artur Koestler - que sofria do mal de Parkinson - também poderia ser atribuído à depressão, mas o que teria levado a sua jovem e saudável esposa a acompanhá-lo no ato? Morrer seria a recusa de uma vida inaceitável para os dois. Ou, ainda, do casal van Dussem que se matou pelas limitações impostas pela idade, deixando escrito: “...pensamos que este éo meIhor modo, o direito de partimos...".

O psiquiatra, uma vez feito o diagnóstico, tem uma preocupação: quer avaliar o risco de suicídio para seu paciente. Para isto apóia-se na literatura.

Como foi visto, o suicídio já foi correlacionado a várias situações - sexo, idade, estado civil e diagnóstico -, bem como a certos traços e estados psicológicos, tais como agressividade, violência e desespero... Apesar da constante discordância entre os resultados das pesquisas quantitativas, os pesquisadores continuam a fazê-las e preocupam-se, com freqüência, com o significado do ato “suicida”. O caráter patológico, ou não, do suicídio e o risco de suicídio podem ser avaliados em função do que representa para a pessoa morrer ou viver. Quem encara a morte como um grande e total silêncio, um repouso, não hesitará diante de um ato que coloca fim a seus sofrimentos. Mas se a morte é um sono com sonhos impõe-se pelo menos uma reflexão, a qual inibe um ser sadio a jogarse no desconhecido. Se, por crença religiosa, os indivíduos acreditam que o suicídio conduz à glória de Deus, ou que leva ao inferno, é de supor que diversa será a atitude diante da morte...

O suicídio pode ser heróico, sagrado ou irrelevante. Para uma pessoa sem objetivos e sem expectativas futuras, o suicídio é considerado como ato imediato, sem questionamentos quanto ao que virá depois, ou o que pensaria amanhã caso não se matasse. Portanto, o suicídio pode ter diversos significados, um para cada paciente, bem como estes podem variar consideravelmente no mesmo paciente.

Alguns de nossos pacientes, após grave tentativa de suicídio, negavam-na, desqualificavam-na, tirando sua responsabilidade do ato. Por sua vez, não foi possível detectar o menor sinal de risco de suicídio em outros pacientes examinados; contudo, logo em seguida, o ato era realizado. Este foi o caso de um dos pacientes que vieram espontaneamente à consulta, segundo ele, para manter-se bem. Não apresentava sinal de que iria matar-se, mas suicidou-se três dias após a consulta.

A análise do conteúdo expresso por seis pacientes deste estudo, afora confirmar que o suicídio também pode ser realizado por pessoas não doentes mentais, mostra que as motivações são as mais variadas. Eles diferem dos suicidas patológicos, nos quais os temas são de certa forma homogeneizados pela doença mental: perseguições, niilismos, desespero que impede o raciocínio e confusão mental.

Nos pacientes entrevistados que foram classificados como suicidas racionais, encontrouse a resolução de acabar com a vida por diversos motivos: fuga ao sofrimento causado por doença sem prognóstico, significando escolha de como morrer; saída romântica de adolescente incapaz de enunciar seu amor, planejando que o anúncio deste, como prova de amor, se desse pela própria morte; opção por parte de pessoas sem coragem de expor atitudes que elas consideram impróprias às pessoas que consideram. Nestes casos, a morte significa a retomada da dignidade e decência, ao invés de perpetuar suas fraquezas diante daqueles que tinham em conta esses indivíduos. Além do mais, há a incapacidade da mulher, ainda jovem, que não via saída para sua insatisfatória situação de vida, vendo na morte a única possibilidade. A morte e o suicídio significavam a saída.

A variabilidade de motivações e significados atribuídos ao suicídio e à morte não parecem ser exclusivas desses pacientes. Reflexões quanto aos significados da morte foram elabo- 
radas por pensadores desde tempos remotos. Cícero (1991), em 45 a.C., em Tusculano, filosofava a respeito da morte, perguntando-se: a alma morre com o corpo como postulavam os estóicos? Ou permanece após a morte corporal e permite ascender a uma vida sem sofrimentos e inquietações? Se os mortos não são infelizes, nós, os vivos, que sabemos que vamos morrer, podemos ter prazer em uma vida precária, que pode acabar a qualquer momento?

Sócrates declarara após a sua condenação: “... uma esperança firmeme anima, juízes, porque ser mandado à morte é felicidade para mim. Deduas coisas, uma: ou a mortenos tira a consciência, ou ela é passagem daqui para outro lugar. Portanto, se a morte é o apagamento de qualquer sentimento e parece um destes sonos sem sonhos que nos trazem às vezes profundo descanso, grandes deuses, quevantagem pre ferir o dia a tal noite..." (Platão, 1999:95). Platão (428-348 a. C.) considerou o suicídio moralmente aceitável. Para Panetius, aluno de Platão, tudo que é gerado destina-se à morte. Este seria o caso das almas também. Nessa mesma época, outros reagem: nada prova que as almas "nascem". Por sua vez, outro aluno de Platão, Aristóteles (384-322 a. C.), qualificou o ato de covardia. Zenon (séc. IV a. C) disse que o homem sábio abandona o banquete da vida justa de maneira direita, em condições justas.

Em certas situações, o suicídio pode ser entendido como ato de extrema nobreza, mas, em outras, como indigno. Ajax, na llíada, mata-se por vergonha. Antônio, vencido, e Cleópatra, para fugirem à escravidão. Seriam covardes, nobres ou loucos?

Dezessete séculos depois, Hamlet parece repetir Sócrates e Cícero em suas dúvidas quanto à morte e ao suicídio. Para os budistas, a morte é irrelevante. Para um samurai (Mishima, 1987), o suicídio é ato de nobreza e liberdade.

Matam-se mesmo adeptos arraigados das religiões cristãs e mosaicas, apesar de nestas ser comum a condenação do suicídio. Nos textos sagrados, ambas as conotações atribuídas ao suicídio são vacilantes. Abimelec pede para ser morto após ter tido seu crânio quebrado por uma mulher. O rei Saul, após a derrota pe-
Ios Filisteus: "para que não venham estes incircuncisos eescarneçam de mi m" (Bíblia Sagrada, 1990:443). Sansão, para matar os Filisteus. Seguem-se vários suicidas heróis e santos: rei Zambí, Aquitoetel, Eleazar, Razis, Santa Apolonia e Santa Pelágia.

Ao longo da história encontramos tanto propostas de condenação quanto de exaltação do suicídio. A morte pode ser vista como silêncio absoluto, como sono que não difere radicalmente da vida ou como caminho do inferno ou do paraíso. É também ambígua para a mesma pessoa: a morte leva para o lado de Deus ou joga no inferno? E, tantas vezes, a dúvida permanece: o que me espera após a morte? Persistem as oscilações entre manifestações opostas.

Diante do suicida que manifesta intenção de novas tentativas temos que estabelecer aproximação com o que a pessoa, nosso paciente, está vivendo. As pesquisas fornecem instrumentos para estudo do caso. É preciso aplicálos ao caso individual, único. A incapacidade de prever o suicídio está relacionada à variabilidade e à inconstância dos significados atribuídos à morte e ao suicídio. Esta angústia e a consciência de nossa impotência podem confortar-nos e fazer com que não tomemos medidas por vezes intempestivas e inefetivas.

O suicídio é fenômeno paradoxal. De um lado aparece como a mais pessoal das ações que um indivíduo pode cometer. De outro, é ubíquo; ocorre ao longo da história humana. Em todos os cantos do mundo e, amiúde, em determinadas circunstâncias demonstra tamanha similaridade, que é possível concluir que os fatores sociais desempenham papel importante, senão decisivo (Diekstra et al., 1989).

O ato suicida é ou a aplicação de uma idéia patológica, ou escolha deliberada de pessoa sem patologia mental. Participam desta decisão elementos que não podem ser quantificados. É preciso estudar, ao lado das pesquisas quantitativas, outros aspectos. A análise dos "significados" é indispensável para o tratamento.

Para a questão do "suicídio", os estudos quantitativos são indispensáveis; para a pessoa "suicida" impõe-se abordagem individual, histórica e qual itativa, afora a abordagem do clínico. 
Referências

ARATÒ, M.; DEMETRE, E.; RIHMER, Z. \& SOMOGYI, H., 1988. Retrospective psychiatric assessment of 200 suicides in Budapest. Acta Psychiatrica Scandinavica, 77:454-456.

BARDIN, L., 1977. Análise de Conteúdo. Lisboa: Edições 70.

BARRACLOUGH, B. \& HUGHES, J., 1987. Suicide: Clinical and Epidemiological Studies. London: Croom Helm.

BARRACLOUGH, B.; BUNCH, J. \& NELSON, B., 1974. A Hundred cases of suicide: Clinical aspects. British Journal of Psychiatry, 125:355-373.

BíBLIA SAGRADA, 1990. Crônicas 10:1. São Paulo: Edição Pastoral.

BLACK, D. W. \& WINOKUR, G., 1990. Suicide and psychiatric diagnosis. In: Suicide Over the Life Cycle: Risk Factors, Assessment and Treatment of Suicidal Patients (S. J. Blumenthal \& D. J. Kupfer, eds.), pp. 135-153, Washington, D.C.: American Psychiatric Press.

CARNEIRO, P. C. \& FIGUEIROA, L., 1994. O tratamento de paciente suicida com depressão maior. Neurobiologia Recife, 57:37-52.

CICERO, 1991. Devant la Mort. Paris: Anlia.

CHENG, A. T. A., 1995. Mental illness and suicide. Archives of General Psychiatry, 52:594-603.

DIEKSTRA, R. F. W., 1993. The epidemiology of suicide and parasuicide. Acta Psychiatrica Scandinavica - Supplementum, 371:9-20.

DIEKSTRA, R. F. W.; MARIS, R. A.; PLATT, S. SCHMIDTKE, A. \& SONECK, G., 1989. Suicide Prevention: The Role of Attitude and Imitation. Leiden: Brill.

GOODWIN, F. K. \& RUNK, B. L., 1992. Suicide intervention: Integration of psychosocial, clinical, and biomedical traditions. In: Suicide and Clinical Practice (D. Jakobs, ed.), pp. 76-93, Washington, D.C.: American Psychiatric Press.

HAWTON, K. \& CATALAN, J., 1987. Attempted Suicide: A Practical Guide to its Nature and Management. 2nd Ed. London: Oxford University Press.

HENRIKSON, M. M.; ARO, H. M.; MARTUNEN, M. J .; HEIKKINEN, M. E.; ISOMETSÄ, E. T.; KUOPASSALMI, K. I. \& LÖNQVIST, J. K., 1993. Mental disorders and comorbidity in suicide. American Journal of Psychiatry, 150:935-940.

HORTON-DEUTSCH, S. L.; CLARK, D. C. \& FARRAN, C. J., 1992. Chronic dyspnea and suicide in elderly men. Hospital Community Psychiatry, 43:11981203.
KLERMAN, G. L. \&WEISSMAN, M. M., 1989. Increasing rates of depression. JAMA, 261:2229-2235.

KING, E., 1994. Suicidal in the mentally ill. British Journal of Psychiatry, 165:658-663.

MATTHEWS, K.; MILNE, S. \& ASHCROFT, G. W., 1994. Role of doctors in the prevention of suicide: The final consultation. British Journal of General Practice, 44:345-348.

MELO, A. L. N., 1981. Psiquiatria. 3a Ed. Rio de Janeiro: Guanabara Koogan.

MELLO, M. F., 1992. Observações e Refl exões sobre a Tentativa de Suicídio em Pacientes Internados em uma Enfermaria de Psiquiatria. Dissertação de Mestrado, São Paulo: Hospital do Servidor Público Estadual.

MELLO, M. F., 1995. O Significado do Suicídio e da Morte para os Pacientes. Tese de Doutorado, São Paulo: Hospital do Servidor Público Estadual.

MISHIMA, Y., 1987. O Hagakura: A Ética dos Samurais eo Japão Moderno. Rio de Janeiro: Editora Rocco.

MURPHY, G. E. \& WETZEL, R. D., 1990. The lifetime risk of suicide in alcoholism. Archives of General Psychiatry, 47:383-392.

PATTON, M. B., 1990. Qualitative Evaluation and Re search Methods. 2nd Ed. Newbury Park: Sage.

ROBINS, E.; MURPHY, G. E. \& WILKINSON, R. H., 1959. Some clinical considerations in the prevention of suicide based on a study of 134 successful suicides. American Journal of Public Health, 49: 888-899.

ROBERTS, J. C. \& KJELLSTRAND, C. M., 1988. Choosing death: Withdrawal of chronic dialysis without medical reason. Acta Psychiatrica Scandinavica, 223:181-186.

PERRONE, J., 1993. Adolescents with cancer: Are they at risk for suicide? Pediatrics Nurse, 19:22-25.

RETTERSTOL, N., 1993. Death due to overdose of antidepressants: Experiences from Norway. Acta Psychiatrica Scandinavica - Supplementum, 371:2832.

SONENREICH, C. \& BASSITT, W., 1979. O Conceito de Psicopatologia. São Paulo: Manole.

VAN EGM OND, M. \& DIEKSTRA, R. F. W., 1989. The predictability of suicidal behaviour: The results of a meta-analysis of published studies. In: Suicide Prevention: The Role of Attitudeand Imitation (R. F. W. Diekstra, ed.), pp. 36-49, Leiden: Brill.

WHO (World Health Organization), 1993. Classificação de Transtornos Mentais e de Comportamento da CID-10. Porto Alegre: Editora Artes Médicas. 